\title{
Radiología intervencional pediátrica en 2012
}

\author{
DIMITRI A. PARRA ROJAS., MD ${ }^{1}$ \\ 1. Profesor Asociado, Universidad de Toronto. Radiólogo Intervencional Pediátrico. División de Terapia Guiada por Imágenes. \\ Departamento de Diagnóstico por Imágenes, Hospital for Sick Children. Toronto, Ontario, Canadá.
}

\begin{abstract}
Pediatric interventional radiology in 2012

Pediatric Interventional Radiology is a specialty with a rapid growth in recent years. This article shows in a summarized fashion an update of the procedures performed in a department dedicated full time to Pediatric Interventional Radiology (IR) in a tertiary pediatric center. For a successful integration of an IR department to a routine practice, it is fundamental to have well trained specialists, an adequate number of cases and collaboration between different specialties to have a multidisciplinary approach to the Patient. Future is promising with the development of new technologies to improve the different imaging modalities and to improve the elements necessary to perform the procedures. We expect more growth of the subspecialty, favoring the use of image guided minimally invasive therapies for the treatment of different pathologic conditions in the pediatric patient.
\end{abstract}

(Key words: Pediatric radiology, interventional radiology.).

Rev Chil Pediatr 2012; 83 (4): 328-335

\section{RESUMEN}

La radiología intervencional pediátrica es una especialidad que ha crecido rápidamente en los últimos años. El presente artículo presenta en forma resumida una actualización de los procedimientos realizados por un servicio dedicado íntegramente a radiología intervencional (RI) pediátrica en un hospital pediátrico terciario. Para una exitosa incorporación de un servicio de RI a la práctica habitual, es fundamental tener especialistas entrenados en el área, un número adecuado de casos y una fluida colaboración entre las diferentes especialidades para realizar una aproximación multidisciplinaria al paciente. El futuro es promisorio, con el desarrollo de nuevas tecnologías para mejorar los métodos de imágenes y perfeccionar los elementos necesarios para realizar los procedimientos. Esperamos un mayor crecimiento de esta subespecialidad, favoreciendo el uso de terapias mínimamente invasivas guiadas por imágenes para el tratamiento de diferentes condiciones patológicas en el paciente pediátrico.

(Palabras clave: Radiología pediátrica, radiología intervencional).

Rev Chil Pediatr 2012; 83 (4): 328-335

Recibido el 30 de julio de 2012, aceptado para publicación el 30 de julio de 2012.

Correspondencia a:

Dimitri A. Parra, MD

E-mail: dimitri.parra@sickkids.ca 


\section{Introducción}

La radiología intervencional pediátrica se ha convertido en una parte importante e insustituible en el hospital pediátrico terciario. Su crecimiento ha sido sostenido, a la par de la tecnología por imágenes, abriendo una serie de alternativas que previamente no eran utilizadas en el manejo del paciente pediátrico.

Hoy en día, el servicio de radiología intervencional idealmente debe contar con diferentes métodos de imagen y los elementos necesarios para realizar intervenciones de alta complejidad. En nuestra institución contamos con cuatro salas de procedimientos, cada una de las cuales cuenta con los mismos estándares de una sala de operaciones, permitiendo realizar, aparte de los procedimientos guiados por imágenes, cualquier tipo de intervención quirúrgica. Cada sala cuenta con fluoroscopia y ultrasonido. Una de ellas cuenta con un equipo de tomografía axial computada (TAC) y en el futuro cercano contaremos con un equipo de resonancia nuclear magnética. Ponemos gran énfasis en reducir al mínimo la exposición a radiación de nuestros pacientes, lo que lo logramos en la calibración de nuestros equipos y en estrategias especificas de protección contra la radiación.

Existen todas las facilidades para realizar laparoscopia y endoscopia, lo que nos permite realizar múltiples intervenciones en conjunto con especialistas de otras áreas. Tratamos de utilizar al máximo el tiempo anestésico de nuestros pacientes, combinando las intervenciones necesarias en un mismo tiempo operatorio. Por ejemplo, en pacientes oncológicos, combinamos la colocación de un vía venosa central realizada por nuestro equipo, con una punción lumbar y biopsia de medula ósea realizada por los oncólogos.

La mayoría del tiempo desempeñamos nuestras funciones en nuestra área, sin embargo la complejidad de algunos pacientes requiere que nos desplacemos frecuentemente a otras unidades como la sala de operaciones o las unidades de tratamiento intensivo pediátrica y neonatal. Visitamos diariamente los pacientes que manejamos en conjunto con otros equipos, para lo cual contamos con el apoyo de un pediatra general que rota tiempo completo con nosotros.
El objetivo del presente reporte es describir brevemente los procedimientos actualmente realizados en una unidad dedicada exclusivamente a radiología intervencional, con más de diez años de experiencia y que realiza entre 9000 y 10000 procedimientos al año.

\section{Acceso vascular}

El acceso vascular es primordial en el tratamiento de múltiples condiciones patológicas. El paciente pediátrico presenta varios desafíos en la obtención de vías vasculares periféricas. Actualmente se dispone de múltiples alternativas de catéteres para distintas funciones ${ }^{1}$ (figura 1 ).

Los catéteres centrales insertados periféricamente (PICC) son frecuentemente utilizados en nuestra institución. Son fundamentales en la unidad intensiva neonatal para la administración de nutrición parenteral y antibióticos. Pacientes con un peso menor a un kilogramo son frecuentes usuarios de nuestros servicios, lo que requiere equipos de alta precisión y experiencia en este tipo de pacientes. El acceso venoso se obtiene utilizado ultrasonido de alta frecuencia y el resto del procedimiento se realiza bajo fluoroscopia. Los PICCs son también utilizados en la administración de nutrición parenteral en pacientes con síndrome de intestino corto, antibióticos en pacientes con osteomielitis y en la administración de quimioterapia en pacientes oncológicos de alto riesgo que se encuentran muy inestables como para recibir un catéter definitivo.

Las vías centrales yugulares son frecuentemente utilizadas para quimioterapia y hemodiálisis. Los puertos de quimioterapia (“Ports”) son también insertados por el radiólogo intervencional en nuestra institución utilizando como acceso la vena yugular interna. Recientemente introdujimos a nuestra practica los "Power Ports" que permiten la inyección de contraste con inyector automático de TAC en pacientes con requerimientos de múltiples estudios tomográficos.

\section{Acceso gastrointestinal}

En nuestra Institución practicamos rutinariamente la inserción de gastrostomías radio- 
lógicas (figura 2A). Usamos el procedimiento retrógrado que consiste en puncionar el estomago desde la superficie cutánea una vez que se ha insuflado con una sonda nasogástrica. Esto se realiza bajo visualización de fluoroscopía y ultrasonografía. Una vez puncionado el estómago se avanza una guía y luego de dilatar el tracto subcutáneo, se avanza el catéter definitivo ${ }^{2}$. Utilizamos gastrostomías de tipo "pig tail" y de bajo perfil "button". En pacientes con significativo reflujo gastroesofágico insertamos gastro-yeyunostomías (figura 2B). Además en los pacientes que no toleran la nutrición intragástrica, podemos fácilmente transformar la gastrostomía en una gastro-yeyunostomía usando el mismo acceso gástrico.

La introducción de las cecostomía a mediados de los años noventa ha mejorado significativamente la calidad de vida de los pacientes
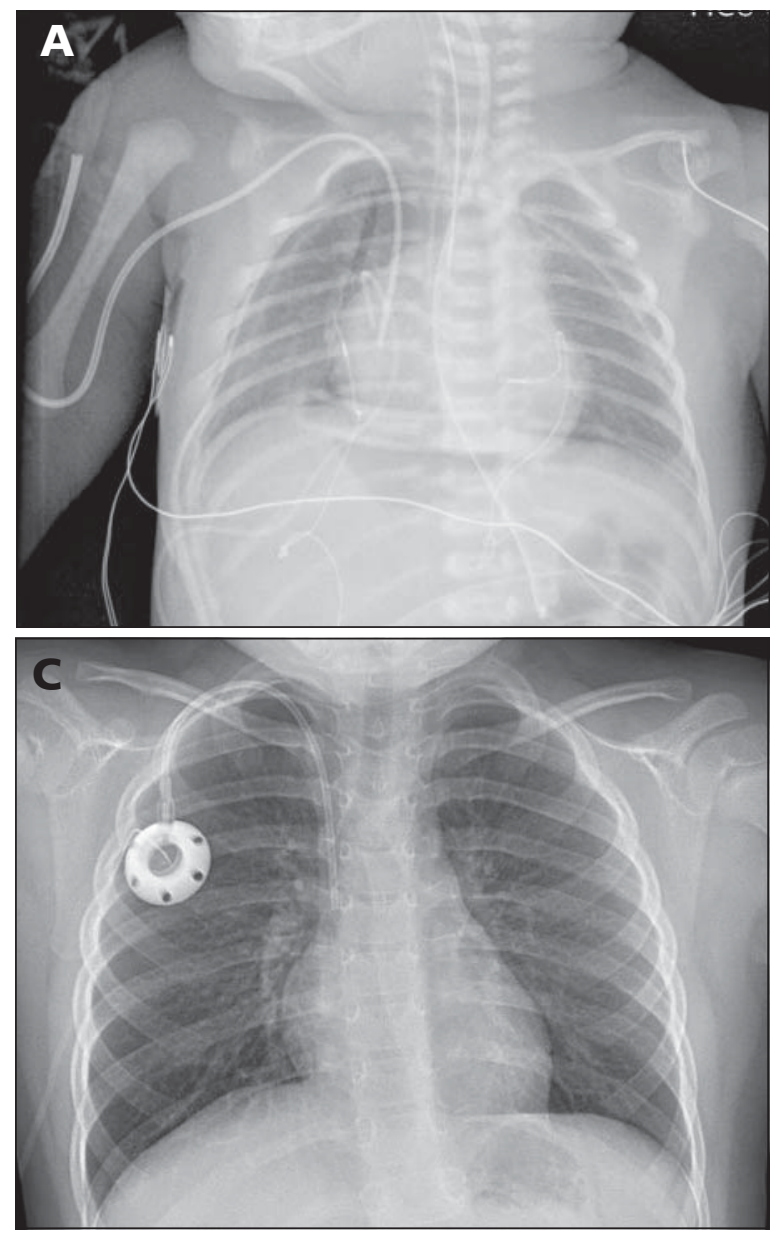

con incontinencia fecal y con patológías como la espina bífida y en especial, mielomeningocele. Usando la guía por imágenes, se instala un catéter en el ciego que permite a los pacientes irrigar el colon en forma planificada (figura 2C) ${ }^{2}$. Especial cuidado se debe poner en los cuidados perioperatorios de estos pacientes, ya que la peritonitis es una complicación que se ve más frecuentemente que en el acceso gastrointestinal alto y puede tener repercusiones severas.

\section{Biopsias}

Hoy en día realizamos una gran variedad de biopsias siendo las más frecuentes las renales y hepáticas, en órganos nativos y trasplantados. Biopsiamos también tumores de partes blandas y de órganos internos. En todos estos

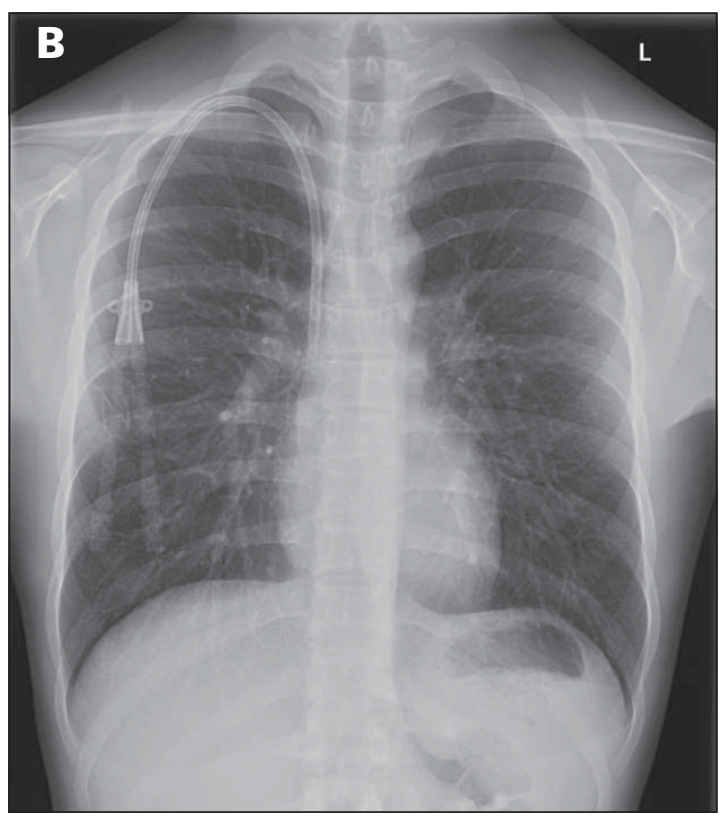

Figura 1. Diferentes alternativas de catéteres para acceso venoso: A. PICC insertado utilizando la vena braquial derecha. B. Catéter de hemodiálisis y C. Port para quimioterapia utilizando la vena yugular interna como acceso. 

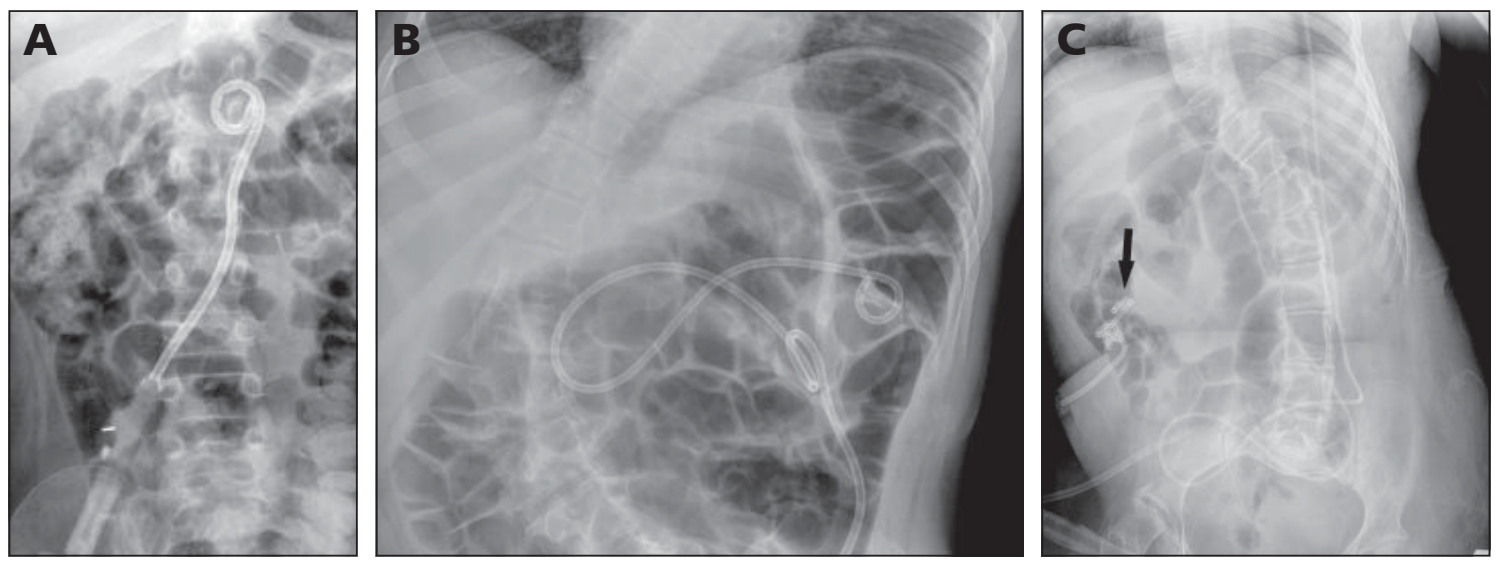

Figura 2. Diferentes alternativas de catéteres para acceso gastrointestinal: A. Gastrostomía radiológica. B. Gastro-yeyunostomía. C. Cecostomía.

casos se utiliza ultrasonografía como guía, lo que ha disminuido significativamente las complicaciones en comparación con las biopsias realizadas sin este método en el pasado. Nódulos pulmonares superficiales también son biopsiados con ultrasonografía.

Las lesiones óseas, retroperitoneales o intra-pélvicas requieres tomografía computarizada como guía. Un área en desarrollo son las biopsias utilizando resonancia magnética. La hemos utilizado principalmente para biopsias de lesiones óseas no visibles en tomografía computada.

Las lesiones pulmonares profundas son abordadas en conjunto con el equipo de cirugía. El nódulo es localizado con tomografía computada, una aguja es avanzada con visualización directa inyectando una solución de azul de metileno y sangre del paciente en el parénquima pulmonar que subyace la lesión. Luego de ello, el equipo de cirugía realiza una toracoscopia y resección del área de preocupación, de acuerdo a la marca hecha por el radiólogo.

En pacientes coagulopáticos o con ascitis intratable y que requieren una biopsia hepática, la realizamos por la vía transyugular. Obteniendo acceso a la vena yugular interna se avanza un catéter rígido a una de las venas hepáticas y se obtiene las muestras a través del catéter, de esta forma no se produce perforación de la cápsula hepática, y de haber sangramiento se mantiene en el compartimiento intravascular.

\section{Manejo de las complicaciones del trasplante}

Las intervenciones guiadas por imágenes son fundamentales en el manejo de las complicaciones del trasplante hepático y renal. Las estenosis biliares son manejadas con dilataciones con balón y colocación de drenajes biliares interno-externos por más de 3 meses (figura 3).

Las complicaciones vasculares son manejadas con angioplastía y en casos de recurrencia, con la colocación de stents. Colecciones peritrasplante son manejadas con drenajes o aspiraciones con uso de ultrasonido. Es fundamental la comunicación fluida entre el cirujano y el radiólogo intervencional para el éxito de estas intervenciones.

\section{Drenajes}

Utilizamos una combinación de ultrasonido y fluoroscopia para realizar una gran variedad de drenajes. Las indicaciones más frecuentes son el derrame pleural paraneumónico o secundario a quilotórax y el drenaje de abscesos intraabdominales secundarios a apendicitis ${ }^{3}$. Además drenamos una gran variedad de abscesos de partes blandas y en otras localizaciones, como el mediastino y el retroperitoneo. En casos de abscesos pelvianos profundos, utilizamos la ruta transrectal, realizando la punción del absceso a través de la mucosa rectal, bajo visualización de ultrasonido endocavitario rectal (figura 4). 

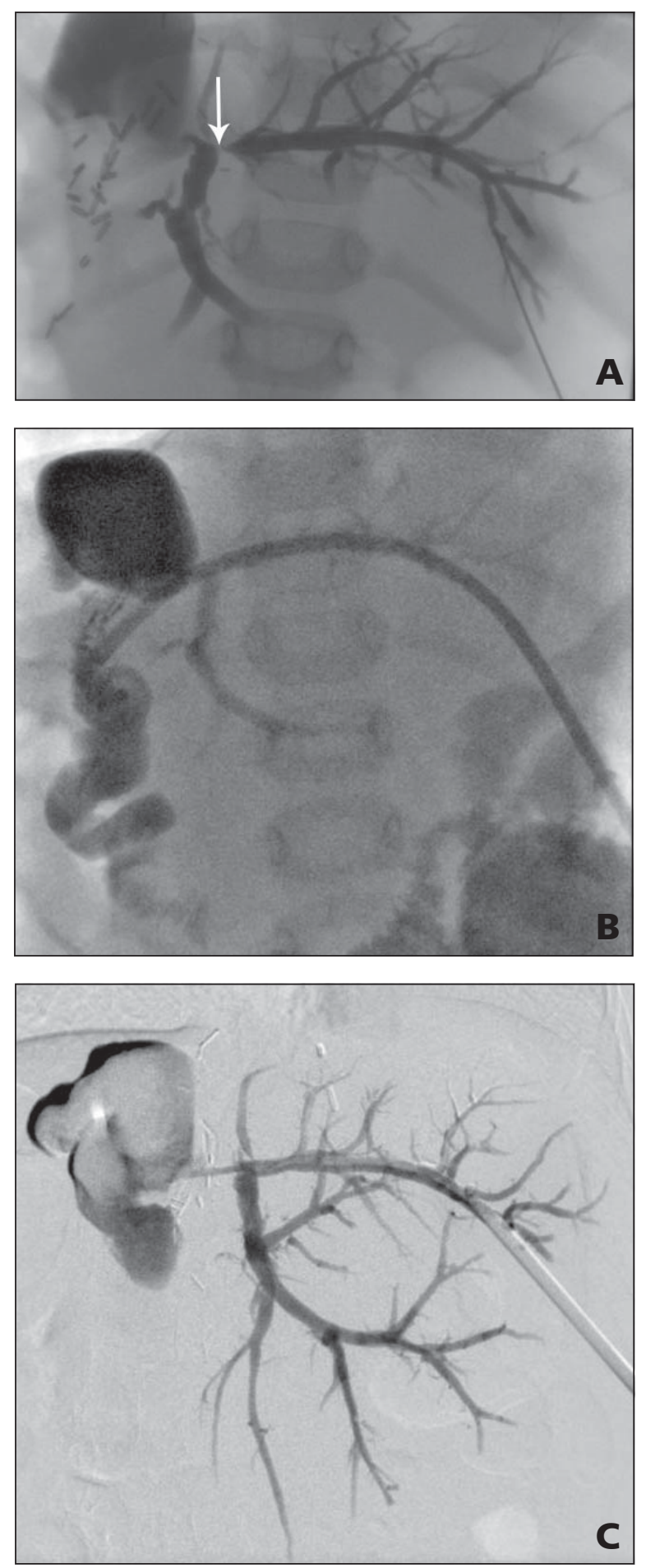

Figura 3. Manejo de estenosis biliar post trasplante. A. Colangiografía percutánea demuestra un área de estenosis biliar (flecha). B. La estenosis es dilatada con un balón y un drenaje biliar es insertado. C. Buen resultado obtenido luego de seis meses de drenaje.
El oportuno drenaje de todos estos tipos de colecciones reduce el tiempo de hospitalización y las complicaciones de los pacientes.

\section{Inyecciones intraarticulares}

La artritis juvenil idiopática es una condición frecuente. Rutinariamente realizamos inyecciones intraarticulares de esteroides usando guía de imágenes. La rodilla, el tobillo y la cadera son las más frecuentemente tratadas utilizando ultrasonido. El codo y hombro requieren artrografía para comprobar la posición de las agujas. Las articulaciones temporomandibulares ${ }^{4}$ (figura 5) y sacro ilíacas requieren el uso de tomografía computalizada.

\section{Tratamiento de la trombosis aguda}

La trombolísis local guiada por catéter ha demostrado ser eficaz en la reducción de las secuelas crónicas de la trombosis venosa $^{5}$. Frecuentemente tratamos trombosis venosa profunda de extremidad inferior y superior. Utilizamos una combinación de trombolísis mecánica y química, utilizando el dispositivo “AngioJet” ${ }^{\circledR}$ (Medrad, USA) y la administración de activador tisular del plasminógeno respectivamente (figura 6). En casos de trombosis extensa debemos instalar filtros de vena cava inferior para prevenir trombo embolismo pulmonar. Somos rigurosos en remover estos filtros dos o tres semanas luego del tratamiento para prevenir complicaciones a largo plazo en la vena cava inferior.

\section{Tratamiento de anomalías vasculares}

Hoy en día, es aceptado que el tratamiento guiado por imágenes es la primera línea terapéutica de la mayoría de las anomalías vasculares. Nuestra institución cuenta con un policlínico de anomalías vasculares en que el radiólogo intervencional, en conjunto con el cirujano plástico, evalúa al paciente y decide el tratamiento más apropiado.

Las anomalías más frecuentemente tratadas son las malformaciones venosas y linfáticas, utilizando tetradecil sulfato só- 

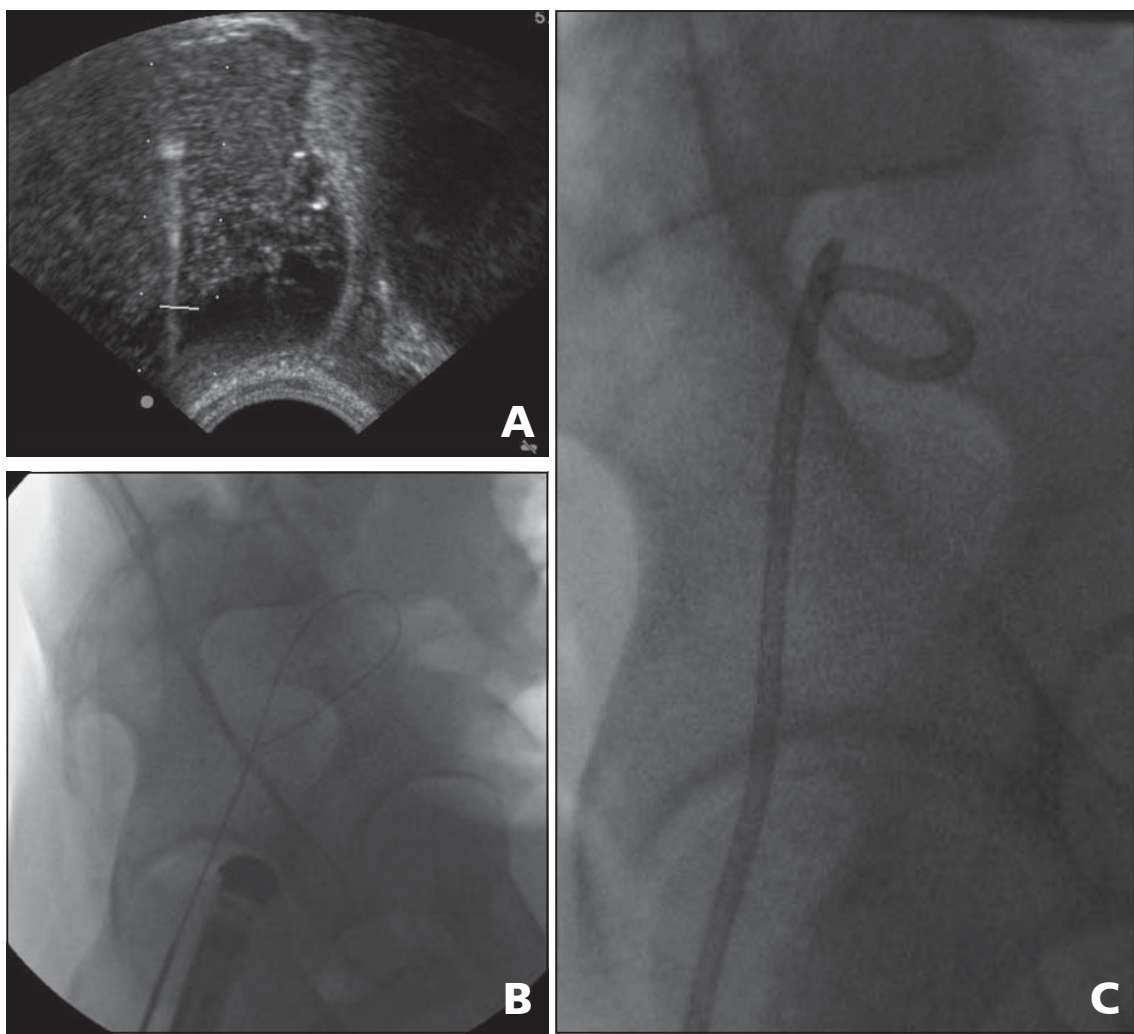

Figura 4. Drenaje Transrectal. A. Utilizando ultrasonido endo-rectal, un absceso pélvico post apendicitis es puncionado. B. Utilizando fluoroscopía y una guía. C. se avanza un catéter que drena todo el contenido del absceso.

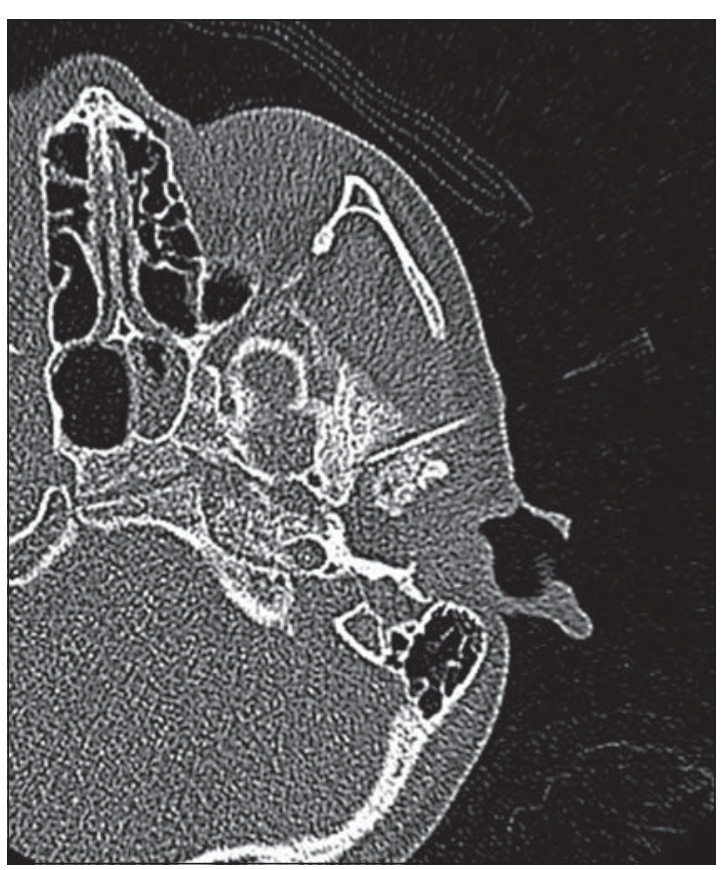

Figura 5. Inyección de esteroide en la articulación temporomandibular utilizando TAC para comprobar adecuada ubicación de las agujas. dico y doxiciclina, respectivamente. Generalmente se requieren múltiples sesiones de tratamiento ${ }^{6}$.

Anomalías vasculares complejas como fistulas arteriovenosas, o síndrome de Klippel Trenaunay, requieren tratamientos más complejos que suelen requerir angiografía y embolización.

\section{Angiografía}

La aparición de la angiografía por tomografía computalizada ha reducido la utilización de la angiografía convencional. La angio-TAC presenta similar o mejor calidad diagnóstica con menos complicaciones y siendo menos invasiva.

Los usos actuales de la angiografía suelen ser terapéuticos en el caso de estenosis de arteria renal, malformaciones vasculares complejas (incluyendo pulmonares), embolización de tumores (terapéutico o pre-quirúrgico) y el manejo del sangramiento agudo.

La administración de quimioterapia y/o ra- 

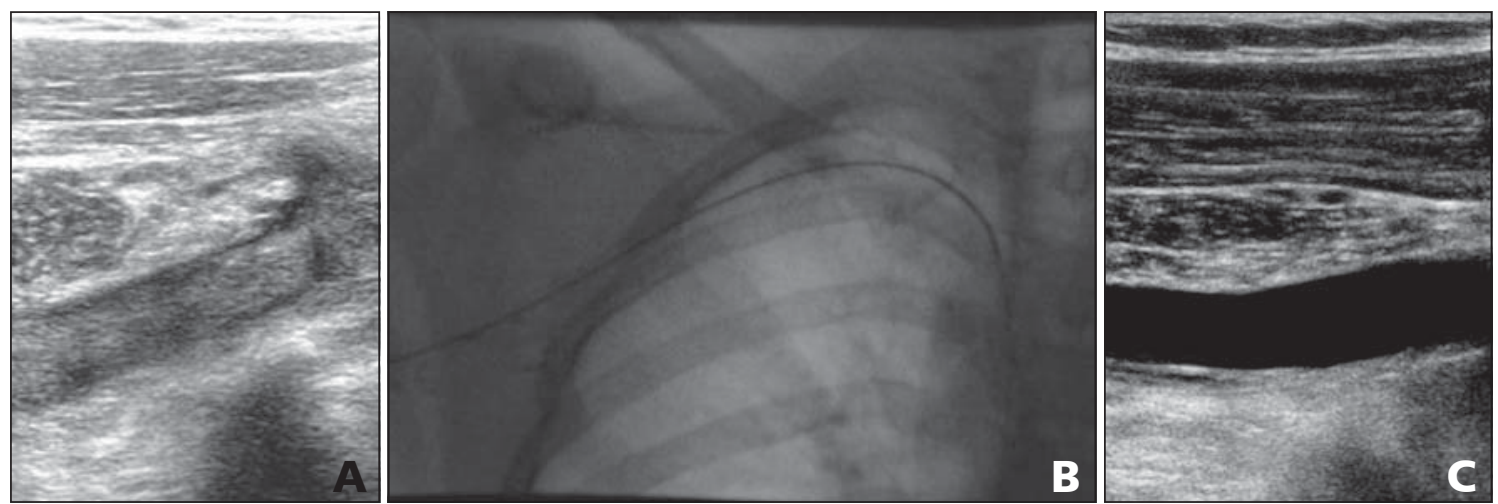

Figura 6. A. Ultrasonido de vena subclavia derecha mostrando signos de trombosis venosa profunda. B. Se realizó una combinación de trombolísis mecánica y química por 72 horas C. Flujo se restableció completamente en la vena y no se observan signos de trombosis.

dioterapia guiada por catéteres es una terapia que ha sido ampliamente utilizada en adultos, especialmente en el manejo del carcinoma hepatocelular. No existe experiencia significativa en pacientes pediátricos. Estas intervenciones constituyen una de nuestras potenciales áreas de desarrollo.

\section{Aplicaciones neuro-intervencionales}

Nuestro equipo cuenta con dos radiólogos neuro-intervencionales que realizan angiografía cerebral diagnóstica y terapéutica, además de punciones lumbares guiadas por imágenes y mielografías por TAC.

\section{Otros procedimientos}

Otra intervención que realizamos es la ablación de osteomas osteoides. En estos casos, usando tomografía computarizada, se avanza una guía a la lesión ósea y una vez que una localización satisfactoria se ha alcanzado, se realiza la ablación, para lo que se puede utilizar láser o radiofrecuencia.

También realizamos embolización de varicocele, usualmente en pacientes con recurrencia luego de cirugía. En estos casos se cateteriza la vena testicular y se realiza una embolización combinando coils y agentes esclerosantes.

En pacientes con litiasis renal severa realizamos nefrolitotomías percutáneas en conjunto con urología. Usando ultrasonido se obtiene acceso percutáneo a la pelvis renal llena de cálculos. Se avanza una guía y se instala un tracto de acceso de una amplitud suficiente como para que el urólogo realice la fragmentación y remoción de los cálculos bajo visualización directa usando un nefroscopio.

\section{Resumen y Conclusión}

La Radiología Intervencional Pediátrica (RIP), como subespecialidad de la Radiología Pediátrica, ha presentado un vertiginoso crecimiento en los últimos años, secundario a una mayor demanda de sus servicios de parte de hospitales pediátricos de alta complejidad.

El presente artículo presenta en forma resumida una actualización de los procedimientos realizados por un servicio dedicado íntegramente a Radiología Intervencional Pediátrica en un hospital pediátrico terciario.

Se espera cada vez un mayor crecimiento de esta subespecialidad, favoreciendo el uso de terapias mínimamente invasivas guiadas por imágenes para el tratamiento de diferentes condiciones patológicas en el paciente pediátrico.

No hay duda que la guía por imágenes es insustituible y hoy en día realizar ciertas intervenciones sin ellas sería impensado. El hecho de que nuestro hospital sea un centro de referencia provincial, nacional e internacional, nos permite contar con un volumen de pacientes importante que requiere el trabajo conjunto de seis radiólogos intervencionales con jornada completa. Es fundamental nuestro compromi- 
so con la educación de diferentes profesionales médicos dentro de nuestra institución, así como también el desarrollo de investigación, fuertemente impulsado por nuestra universidad.

Para una exitosa incorporación de un Servicio de Radiología Intervencional Pediátrico a la práctica habitual, es fundamental tener especialistas entrenados en el área, un número adecuado de casos y una fluida colaboración entre las diferentes especialidades para realizar una aproximación multidisciplinaria al paciente.

El futuro es promisorio con el desarrollo de nuevas técnicas y equipamientos que permitirán intervenciones más seguras y exitosas. La comunicación entre las diferencias especialidades es fundamental y repercute significativamente en el óptimo cuidado del paciente.

Quizás el mayor desafío hoy en día es comenzar la práctica de radiología intervencional pediátrica donde no existe, para ello se requiere realizar una formación adecuada de los profesionales involucrados, cooperación con otras unidades y recursos humanos y tecnológicos. Una vez establecido el equipo y los vínculos, no hay marcha atrás, sino una constante mejo- ría de la calidad de vida de nuestros pacientes y sus familias.

\section{Referencias}

1.- Chait PG, Temple M, Connolly B, John P, Restrepo R, Amaral JG: Pediatric interventional venous access. Tech Vasc Interv Radiol 2002; 5 (2): 95-102.

2.- Connolly BL: Gastrointestinal interventions--emphasis on children. Tech Vasc Interv Radiol 2003; 6 (4): 18291.

3.- McCann JW, Maroo S, Wales $P$, et al: Image-guided drainage of multiple intraabdominal abscesses in children with perforated appendicitis: an alternative to laparotomy. Pediatr Radiol 2008; 38 (6): 661-8.

4.- Parra DA, Chan M, Krishnamurthy G, et al: Use and accuracy of US guidance for image-guided injections of the temporomandibular joints in children with arthritis. Pediatr Radiol 2010; 40 (9): 1498-504.

5.- Temple M, Williams S, John P, Chait P, Connolly B: Percutaneous treatment of pediatric thrombosis. Eur $\mathrm{J}$ Radiol 2005; 53 (1): 14-21.

6.- Burrows P, Mason K: Percutaneous Treatment of Low Flow Vascular Malformations. J Vasc Interv Radiol 2004; 15: 431-45. 